\title{
Aristóteles e a história, mais uma vez*
}

\author{
Aristotle and History Once More
}

\author{
François Hartog \\ hartog@ehess.fr \\ Professor \\ École des Hautes Études en Sciences Sociales \\ Bureau 544 \\ 190-198, avenue de France, 75244 \\ Cedex 13 - Paris \\ France
}

\section{Resumo}

O objetivo deste artigo é o de analisar algumas questões e desdobramentos para a escrita da história provenientes da chamada virada liguística na história. Mais do que reconstituir os percursos que caracterizam essa virada, ou delimitar seus contornos, nos propomos a observar o ponto de oscilação ou o contra-ataque brusco marcados pela publicação, em 1992, do livro Probing the Limits of Representation, editado por Saul Friedländer, colocando em paralelo os estudos mais recentes de Paul Ricœur e Carlo Ginzburg e destacando suas respectivas leituras das obras clássicas de Aristóteles, a Poética e a Retórica, mediadas pela leitura de Hayden White.

\section{Palavras-chave}

14 Giro linguístico; Historiografia; Escrita da história.

\begin{abstract}
This article aims to analyze some questions and developments for the writing of History stemming from the so-called linguistic turn in History. More than re-establishing the paths which define this turn, or circumscribing its outlines, we propose to observe the unsteadiness or the harsh counterattack indicated in the publication of the book Probing the Limits of Representation, edited by Saul Friedländer in 1992, by making a parallel with recent works of Paul Ricoeur and Carlo Ginzburg, and to emphasize their own readings of the classic pieces of Aristotle, the Poetics and the Rethoric, mediated by Hayden White's reading.
\end{abstract}

Keywords

Linguistic turn; Historiography; History writing.

Recebido em: 27/11/2013

Autor convidado

\footnotetext{
* Entre o Brasil, a Alemanha e a França, Manoel Salgado circulava. Ele soube, no espaço de alguns anos, tecer fortes laços. Durante suas estadas em Paris, ele passava pelo meu seminário, e sua conversa simples e amigável muito me ensinou sobre a história do Brasil e no Brasil. Quando eu estive no Rio, na UFRJ, para um workshop com doutorandos, ele soube fazer deste encontro um belo momento de camaradagem intelectual. A última vez que o vi, foi em São Paulo. Ele estava cheio de entusiasmo, de sorrisos e de projetos. Depoimento de François Hartog. Paris, 22 de outubro de 2013.

Este artigo foi publicado originalmente em Critique, Paris, juin-juillet, 2011, p. 540-552. Agradecemos ao professor Hartog e aos editores da revista a autorização para a presente tradução, realizada por Eliane Misiak (FURG). Agradecemos também a Eliete Lúcia Tiburski pela formatação final e ajuste do texto às normas, e a Marina Araújo pela tradução do resumo. Agradecemos, finalmente, à Direção do IFCH da UFRGS pelo financiamento que viabilizou a tradução. Revisão técnica de Temístocles Cezar.
} 
O linguistic turn is over. ${ }^{1}$ Desde quando? Ainda se discute. Certos historiadores dirão, inclusive, que ele jamais começou! Como havia constatado Péguy em Clio: obstinamo-nos com uma questão durante quinze ou vinte anos e, "de repente, damos as costas". "Não sabemos mais do que falávamos". Há pouco tempo, foi-me relatado que, atualmente, nas universidades americanas, os jovens estudantes de história não sabem mais do que se trata, enquanto que seus professores Ihes falam somente de arquivos. Seja como for, recentemente, duas historiadoras, interrogando-se sobre o estado de suas disciplinas, constatam seu refluxo, como uma onda que acaba de se retirar antes que a próxima quebre. Em seu discurso sobre o estado da história, Gabriele Spiegel, presidente da American Historical Association no ano de 2009, começa lembrando que o termo (linguistic turn) aparece em 1965, com o filósofo Richard Rorty, antes de avaliar qual foi seu impacto e de se interrogar sobre o que resta dele nos questionários e nas maneiras de trabalhar dos historiadores hoje (SPIEGEL 2009). Do mesmo modo, Caroline Baynum, professora de história medieval do Instituto de Estudos Avançados de Princeton, dedica-se a um rápido inventário de todos os turns e returns propostos ou proclamados desde o primeiro da série, aquele da linguística dos anos 1960 (BYNUM 2000).

Como não faz parte do meu propósito reconstituir os percursos dessas viradas, nem delimitar seus contornos, limitar-me-ei a observar este ponto de oscilação ou este contra-ataque brusco marcados pela publicação, em 1992, do livro Probing the Limits of Representation, editado por Saul Friedländer (FRIEDLÄNDER 1992). O objetivo era o de interrogar as consequências do relativismo pós-moderno e de indagar os equívocos que ele mantém sobre a questão do real e da verdade histórica, a respeito "deste acontecimento limite" que foi o Holocausto. É nessa ocasião que Carlo Ginzburg conduz o ataque final contra as posições de Hayden White, contra quem Arnaldo Momigliano havia, pela primeira vez, iniciado as hostilidades em 1981 (MOMIGLIANO 1984). Apesar de seus esforços, Hayden White não poderá sair das aporias de sua posição tropológica, de seu pantropologismo e, em pouco tempo, Paul Ricœur, pouco suspeito de desconfiança em relação às abordagens narrativistas, concluirá por um "impasse" e pela "suspeita legítima quanto à capacidade dessa teoria retórica de traçar uma linha limite entre narrativa histórica e narrativa de ficção" (RICFUR 2000, p. 328).

Para falar a verdade, essa questão dita, frequentemente, da história e da ficção é apenas uma expressão local e relativamente tardia de um movimento muito mais amplo, nem simples, nem unívoco, mais dramático também, e iniciado bem mais cedo, de interrrogações sobre esta que é "a mais nobre e mais misteriosa faculdade do homem", a linguagem (BENVENISTE 1966, p. 45). Iniciado, pelo menos na França, com Mallarmé e Rimbaud, continuado por Maurice Blanchot (leitor de Kafka e amigo de Levinas), em cuja obra tantos fios se entrelaçam, ele se estendeu sobre um século aproximadamente e tomou formas

1 "A virada linguística acabou". Todas as expressões em línguas estrangeira seguem de acordo com o original (Nota do revisor). 
diversas até o estruturalismo dos anos 1960 e os pós- que se seguiram. Ainda que os principais protagonistas distanciem-se rapidamente dessas apelações, subsiste que a linguagem, essa linguagem que sempre escapa, permanece no centro.

O que fez com que, na Europa, a linguagem tenha sido metódica e apaixonadamente escrutada? O que fez com que, após a publicação do Curso de Saussure, em 1916 (em plena guerra), a linguística, com a distinção entre língua e fala, tenha se tornado, progressivamente, a ciência piloto das ciências humanas? Celebrando Saussure, em 1963, por ocasião do cinquentenário de sua morte, Émile Benveniste sublinhava "o alcance desse princípio do signo instaurado como unidade da língua [...]. Ora, vemos agora se propagar esse princípio para fora das disciplinas linguísticas e penetrar nas ciências do homem, que tomam consciência da sua própria semiótica. Não é a língua que se dilui na sociedade, é a sociedade que começa a reconhecer-se como 'língua'" (BENVENISTE 1966, p. 43). O que fez ainda com que, após 1945, a linguagem, sempre ela, tenha sido tida por quase tudo, sem deixar de ser associada à falta, à ausência, ao silêncio e à morte? "Aquilo que não se pode dizer, é preciso calar", dizia Wittgenstein, "(não) é preciso calar", corrige Jacques Derrida (PEETERS 2010, p. 204). A essas colocações fazem eco as últimas palavras de Blanchot, em Après coup, "mesmo sobre a morte sem frases, ainda é preciso meditar, talvez sem fim, até o fim" (BLANCHOT 1983, p. 100). Responder a tais questões, arriscar-se apenas, excederia não apenas o espaço de um artigo, mas também minhas capacidades. Entretanto, creio que ao negligenciar esse movimento profundo, complexo, corre-se o risco de, como dizia Péguy, não mais compreender do que se falava, quando Roland Barthes, por exemplo, escrevia que "o fato tem tão somente uma existência linguística". Caso contrário, o propósito, retirado de seu contexto, oscila entre trivialidade e absurdidade (BARTHES 1984).

\section{Narrativa, retórica, história}

Para retornar à história e as suas formas de negociar a virada linguística, pode ser esclarecedor traçar um paralelo entre duas abordagens, certamente bem diferentes, mas que possuem em comum o fato de interrogar, no curso dos anos 1980, os poderes da narrativa. Paul Ricœur publica Tempo e Narrativa entre 1983 e 1985. A partir de 1984, Carlo Ginzburg engaja-se em um combate, jamais abandonado, contra aqueles que ele chama, desde então, de céticos. ${ }^{2} \mathrm{Nada}$ de equívoco: o único objetivo dessa projeção é o de convidar a considerar suas démarches como duas maneiras de apreender uma conjuntura e de replicá-la, de modo algum de associá-las, e menos ainda de opô-las: o defensor do realismo face ao advogado da narrativa!

Com relação à história, um deles é um outsider. Ele traça seu caminho filosófico, e aprofunda a enquete sobre as capacidades da narrativa, não por complacência com uma moda, mas por preocupação em aproximar ao máximo possível as aporias do tempo e experimentar, simultaneamente, os limites da narrativa. Ele mobiliza, torna útil esse saber renovado e recente, em plena

\footnotetext{
2 Ver seu prefácio à Natalie Zemon Davis, Le retour de Martin Guerre, reeditado em anexo em Le fil et les Traces.
} 
elaboração, com vistas a explorar as potencialidades da narrativa. Ele é também o outsider que mais se aproximou da história. Ele leu os historiadores, não para anexá-los ou para fazer filosofia da história pelas suas costas, mas com vistas a, graças a eles, aprofundar seu questionário filosófico. Se é verdadeiro que o tempo pensado somente existe quando narrado, é imperativo demostrar que mesmo a história, que pretende ter rompido com a narrativa, aquela dos Annales (para resumir), conservou, se observarmos de perto, um elo, ainda que tênue, com ela. Tal é o caso deste "manifesto" que é o Mediterrâneo de Braudel. Bastava ousar dizê-lo para que isso se tornasse evidente.

O outro é um insider: no coração da disciplina, historiador da época moderna, ele, rapidamente, encontrou-se em posição de falar por ela. Com esta particularidade: ele está longe de ser o inimigo da narrativa. Realista, sim, mas em nada positivista. Tivesse sido ele um historiador preocupado sobretudo em enumerar, teria tido, é verdade, menos razões para inquietar-se com as formas de ler. Em seus livros e artigos, ele, de fato, não cessou de confrontar-se com a questão da narrativa, quer se trate da questão da forma de interrogar suas fontes (os arquivos dos processos de feitiçaria), de delimitar aquilo que ele chama, em História noturna: decifrando o sabá, de "núcleo narrativo elementar que acompanhou a humanidade durante milênios" (GINZBURG 1992, p. 284). Persistentemente, ele se pretende atento às "possibilidades cognitivas de qualquer narrativa, incluindo-se todas as formas de historiografia". A respeito de $A$ educação sentimental, ele se dedica a valorizar a "riqueza cognitiva da obra de Flaubert" (GINZBURG 2003, p. 97); ou, estudando uma Histoire des îles Mariannes, publicada, em 1700, por um jesuíta, ele observa que os textos têm "fendas" das quais se pode ver "sair o real" e que "falar de realidades situadas fora do texto seria uma ingenuidade positivista" (GINZBURG 2003, p. 82). Mais ainda, e, desta vez, colocando-se antes do texto acabado, ele estima que um lugar deve ser dado às "interações entre dados empíricos e restrições narrativas no interior do processo de pesquisa" (GINZBURG 2003, p. 95). Se considerarmos a forma de conceber seu papel de historiador, o próprio título de seu último livro o exprime: O fio e os rastros. Por fio é preciso compreender, claramente, precisa o autor, o "fio" da narrativa. "Procuro contar, servindo-me dos rastros, histórias verdadeiras (que às vezes têm como objeto o falso)" (GINZBURG 2010, p. 7).

Ricœur leu Ginzburg. Este último está presente em dois momentos de A memória, a história, o esquecimento: na parte consagrada à epistemologia histórica e naquela dedicada à condição histórica. O "paradigma indiciário", o prefácio a Lorenzo Valla (sobre retórica e filologia), O Juiz e o historiador (com a questão da prova) e, finalmente, o "impasse" tropológico de Hayden White, são todos elementos que possuem lugar na reflexão do filósofo. A recíproca se verifica? No meu entender, não. O historiador não menciona e não discute os trabalhos de Ricœur. ${ }^{3}$ O que é um direito seu. Em todo caso, trata-se de um indício de que ele não precisou desse filósofo que, durante aproximadamente 
vinte anos, interrogou-se sobre "a inquietante estranheza da história" (HARTOG 2011, p. 65).

Tanto um quanto outro se deparam com a questão da representação, aquela da lancinante interrogação sobre a relação entre o passado real e o conhecimento histórico, aquela sobre a qual a fórmula de Ranke, mil vezes repetida, do wie es eigentlich gewesen terminou por dispensar a reflexão. Ricœur detêm-se longamente sobre ela em Tempo e Narrativa; Ginzburg consagra-Ihe um artigo: "Representação, a palavra, a ideia, a coisa", primeiramente publicado nos Annales, em 1991. Questionar o uso da palavra e todos os "jogos de espelho" que ela permite entre ausência e presença, em um momento em que se exige uma história das representações, particularmente nos Annales e à volta, é, evidentemente, apropriado. Segue um percurso virtuoso que, em poucas páginas, conduz o leitor ignorante da primeira aparição da palavra no Dictionnaire de Furetière, no qual "representação" é empregado no contexto dos funerais reais (para designar seja um manequim do rei defunto, seja um leito funerário vazio e simplesmente recoberto por uma mortalha), até as interrogações sobre os efeitos da presença real na eucaristia, passando pelo Colosso grego (GINZBURG 1998, p. 73-88). Insatisfeito, por sua vez, com o conceito de representação, Ricœur forja um outro, o de "representância", que ele reconhece ser "difícil". Para abordar essa relação, que ele qualifica de "enigma", ele recorre, sucessivamente, às categorias do Mesmo, do Outro e do Análogo, que são três maneiras de decompor e, depois, de sintetizar a visada do discurso histórico em relação a seu "vis-à-vis" terminado, qualificado de "alusivo" e "imperioso" simultaneamente (RICFUR 1985, p. 269). Pois se o historiador é um "mestre de intrigas", ele é, ao mesmo tempo, "um servidor da dívida para com os mortos".

Pelos caminhos que levam do Mesmo ao Outro, ao Análogo, Ricœur encontra, inevitavelmente, Hayden White, o mestre ès tropos, cujo livro, rapidamente famoso, Metahistory, é qualificado por ele de "poética da historiografia". Para White, leitor de Vico, a retórica é, com efeito, o núcleo da criatividade da linguagem e o troping é, diz ele, "a alma do discurso". Sua Metahistory poderia intitular-se igualmente Pre-History, na medida em que o recurso a um ou outro tropo prefigura uma narrativa possível, de modo que da dispersão daquilo que ainda não foi narrado emerge uma forma e um sentido: uma narração e uma explicação. O único ponto que gostaria de evidenciar aqui é que, fazendo isso, White engloba a poética na retórica ou faz da poética "a alma" da retórica. 0 que, do ponto de vista da narrativa histórica, tem por primeira consequência ignorar a velha interdição colocada por Aristóteles, para quem a história, não sendo uma arte mimética, não pertence à poiesis.

Para Ginzburg, o encontro se faz por meio do artigo de Momigliano "The History of Rhetoric and Rhetoric of History: on Hayden White's Tropes" que, em 1981, abriu seus olhos para as consequências das posições do autor de Metahistory. Pouco me importa, diz, basicamente, Momigliano, se tais historiadores usam a metonímia ou a sinédoque, pois a única coisa que conta é que "suas histórias devem ser verdadeiras" (MOMIGLIANO 1984, p. 51). 
Quanto às relações entre retórica e história, se elas iniciaram com Isócrates, seria necessário, pelo menos, considerar o fato de que elas foram ambivalentes ao longo da Antiguidade e que, em um certo momento, na época moderna, elas foram cortadas. Em resumo, sem o apoio de uma história séria da retórica, as considerações sobre retórica e história permanecem muito etéreas. Em todo caso, a associação entre Hayden White e a retórica sai ainda fortalecida por sua inscrição em uma linhagem que inicia com Isócrates. Mais do que de uma virada linguística, dever-se-ia falar de "virada retórica", propõe então Ginzburg.

\section{Aristóteles, mais uma vez}

Sem que seja necessário estender-me mais sobre as posições de Hayden White, sobre a leitura rigorosa feita por Ricœur ou sobre as críticas reiteradas de Ginzburg, o leitor terá compreendido que o White de Ricœur está mais do lado da poética, enquanto que aquele de Ginzburg está, primeiramente, do lado da retórica. Nesse ponto, o leitor também terá compreendido que aquele que, desde o início, encontra-se no plano de fundo e que, de fato, torna possível (e espero pertinente) o paralelo esboçado não é outro senão Aristóteles, como autor da Poética, naturalmente, mas também da Retórica.

Ambos, de fato, cedem-lhe lugar, mas eles não se dirigem ao mesmo Aristóteles. Ricœur reconhece, imediatamente, que "o impulso inicial" de Tempo e Narrativa veio da Poética. O que, de maneira alguma, é evidente, visto que na Poética não se tratava diretamente da questão do tempo! Por outro lado, retém toda a sua atenção "a composição da intriga promovida por Aristóteles à posição de categoria dominante na arte de compor obras que imitam uma ação". É o que Ihe permite "extrair da Poética o modelo de composição da intriga" que ele se proporá "a estender a toda composição que chamamos narrativa" (RICCEUR 1983, p. 61, 317). Incluindo, portanto, a história. Quanto a Ginzburg, se ele conhece, evidentemente, as anotações da Poética sobre a história, ele está mais interessado na Retórica. Por quê? Por duas razões ao menos. Primeiramente, porque White, após Roland Barthes, reabre, de forma ruidosa, a questão dos laços entre retórica e história. Depois, porque ao lado da retórica de Isócrates, existe aquela de Aristóteles, para quem a questão da prova é central. Em outras palavras, a) contrariamente ao que imaginam os céticos e outros pós-modernos, a retórica não se reduz à arte de persuadir, ${ }^{4}$ b) retórica e provas podem estar e estiveram estreitamente ligadas. Porque se demonstra com o auxílio do entimema, que é o silogismo da retórica, e o entimema é, para Aristóteles, "o corpo da prova" (Aristóteles, Rhétorique 1354a, 15).

Tal ponto atingido, que se aparenta um pouco a um puxão do tapete sob os pés do adversário (ainda que Hayden White não recorra à retórica de Aristóteles), Ginzburg vai, nitidamente, mais longe. Em "Aristóteles e a história, mais uma vez", ele procura mostrar que a arqueologia (no sentido dos primeiros capítulos de Tucídides) e a retórica (no sentido de Aristóteles) partilham a mesma 
preocupação com a prova e recorrem ao entimema, de modo que "retórica, história e prova estão estreitamente ligadas na Grécia do século IV" (GINZBURG 2003, p. 51). Quando, como continuador de Híppias (o sofista zombado por Platão), ao estabelecer uma primeira lista de vencedores olímpicos, Aristóteles faz-se epigrafista e compila uma lista de vencedores nos jogos píticos, ele pratica a arqueologia (essa história posteriormente será nomeada antiquária). Em sua arqueologia, Tucídides serviu-se, "várias vezes", desse modo de conhecimento que recorre a entimemas. "Se [portanto] supormos que a dimensão arqueológica da obra de Tucídides pode ter suscitado o interesse de Aristóteles, a atitude desse último com relação à história poderia ser reexaminada à luz das alusões a um conhecimento inferencial do passado presentes na Retórica" (GINZBURG 2003, p. 51). A Retórica poderia, assim, permitir revisar o julgamento (aparentemente definitivo) da Poética sobre a história. Pode, então, surgir a conclusão (que não deixaria de surpreender o leitor que teria perdido o que precede): "a obra em cuja qual Aristóteles fala mais detidamente da historiografia (ou, ao menos, de seu núcleo fundamental), no sentido em que a entendemos, não é sua Poética, mas sua Retórica" (GINZBURG 2003, p. 43) .

Detenhamo-nos, então, um instante sobre os primeiros capítulos de Tucídides, que ocupam um lugar importante no raciocínio. De fato, eles lembram uma proeza, na medida em que eles são, ao mesmo tempo, a tentativa mais refletida e acabada de reconstruir os tempos antigos da Grécia e a demonstração definitiva que uma história científica (para empregar um termo moderno) do 20 passado é, de fato, impossível. Baseando-se em indícios (semeia), reunindo e confrontando elementos de prova (tekmêria), o historiador pode suprimir o falso, circunscrever o mítico (muthôdes), "encontrar" fatos e, o melhor, chegar a uma convicção (pistis), mas não a um conhecimento claro e distinto. "Ora, as coisas anteriores e mesmo as que eram ainda mais antigas era impossível descobrir com clareza, em vista da grande distância temporal, mas, a partir do que sou levado a crer, examinando os indícios de um longuíssimo período, não considero que foram grandes nem com relação a guerras, nem com relação a mais nada" (HARTOG 1999, p. 59).

O objetivo perseguido por essa reconstrução é, portanto, duplo: provar que em comparação à guerra presente - que Tucídides, imediatamente, estimou como devendo ser a maior -, todos os conflitos do passado são inferiores (estamos no registro da amplificação, cuja Retórica de Aristóteles tornará o traço característico do discurso epidídico); convencer por meio do exemplo que somente a história contemporânea importa realmente, porque ela é a verdadeira ciência política. ${ }^{5}$ Acrescentemos ainda que o modelo, que serve de padrão para a reconstrução dos tempos distantes, é o da potência (dunamis) ateniense atual, com seus três componentes (o dinheiro, a frota e as muralhas). De Agamêmnon até Polícrates, o tirano de Samos, passando pelo rei Minos, trata-se de uma mesma história de dinheiro, frota e muralhas, compreendendo-se que o império 
ateniense representa a sua versão mais acabada. Atenas é o telos: vai-se do presente ao passado (inferior), revelando um modelo de inteligibilidade que depende mais de uma teoria do poder do que de uma história antiquária.

O entimema, definido como o cerne da prova, é suficiente para ligar a história e a retórica a ponto de sustentar que é na Retórica que Aristóteles fala mais prolongadamente de história? À primeira vista, entretanto, ele não Ihe atribui nenhum lugar específico. Os discursos se repartem, com efeito, em três gêneros, o deliberativo, o judiciário e o epidídico. Cada um visa um ouvinte, que se encontra em posição de juiz. O deliberativo está voltado para o futuro, o judiciário, para o passado e o epidídico inscreve-se no presente. Mais tarde, a história tenderá a ser inspirada pelo epidídico (veremos Políbio batalhar contra e Luciano sustentar que uma "muralha" separa a história do elogio, enquanto outros proporão um quarto gênero para a história).

A enquete de tipo histórica aparece, todavia, na Retórica, por ocasião do exame dos temas sobre os quais se delibera e para os quais é útil munir-se de argumentos. Assim, em matéria de receitas da cidade, é necessário estender sua experiência conduzindo uma enquete histórica sobre o que se praticou em outro lugar (Aristóteles, Rhétorique 1359b, 32). Do mesmo modo, naquilo que concerne à guerra e à paz, é necessário ter examinado (theôrein) as guerras conduzidas pela cidade mas também pelas outras (Aristóteles, Rhétorique $1360 a, 4)$. No que diz respeito, finalmente, à constituição e às leis, não somente é útil ter um conhecimento "teórico" desses assuntos, mas também ter conduzido enquetes de campo no estrangeiro. "As relações de viagem são, assim, evidentemente úteis para a legislação [...] como as enquetes (historiai) daqueles que escrevem sobre as ações humanas o são para as deliberções políticas" (Aristóteles, Rhétorique 1360a, 33-37). Eis a parte reconhecida a essas enquetes, concebidas como coletas de dados e destinadas a fornecer premissas, permitindo argumentar corretamente no âmbito das deliberações da assembléia. E, a Aritóteles, concluir com esta precisão, que não é desprovida de importância. "Mas tudo isso (essas enquetes), é assunto da política, não da retórica" (Aristóteles, Rhétorique 1360a, 37). Elas visam fornecer premissas instruídas com o objetivo de formular conselhos, que são a própria finalidade do gênero deliberativo. Estamos, portanto, longe de Heródoto, mas também longe de Tucídides, não francamente na arqueologia, mas muito próximo, por outro lado, da coleção das cento e cinquenta e oito constituições coletadas por Aristóteles e por seus alunos.

Para Ricœur, o texto central de sua meditação sobre a narrativa e, portanto, sobre a história, é, certamente, a Poética, na qual ele vê o modelo de composição da intriga que ele se propõe a estender a toda composição narrativa, como vimos, quer se trate de história ou de ficção. Essa extensão é seu direito mais estrito. Mas ele infringe, ao mesmo tempo (assim como Hayden White), a interdição aristotélica. Pois Aristóteles (e limitar-me-ei aqui unicamente a esses pontos) indica, da maneira mais clara possível, que a história, a dos historiadores (historikoi), não ascende nem à poiesis nem à mimesis, reservadas ao poeta. Não esqueçamos que a história não está aqui por ela mesma, mas apenas como 
vis-à-vis, para exaltar a tragédia. É poeta não tanto aquele que se expressa em versos, mas aquele que compõe narrativas (muthoi), intrigas (traduz Ricœur): "É claro, a partir do que foi dito, que não é obra do poeta dizer o que aconteceu, mas o que poderia acontecer -, e o possível é conforme o verossímel ou o necessário" (HARTOG 1999, p. 109). Seguramente, não se deve esperar nada assim do historiador: ele diz e somente pode dizer aquilo que se passou. Ele diz os fatos (legei ta genomena) da melhor maneira, em sua sucessão. Como ele poderia "fazê-los" (poiein ta genomena)? Naturalmente, não no sentido de forjá-los totalmente, mas no sentido de compor uma narrativa representando uma ação única e que forma um todo, do qual não se pode mover nem retirar nenhum elemento?

Aristóteles apresenta uma prova suplementar dessa separação ao imaginar o seguinte caso. Suponhamos que um poeta efabule "o que aconteceu, nem por isto é menos poeta, pois nada impede que algumas coisas que aconteceram sejam tais que tenham sido verossímeis e possíveis. É por isso que ele é poeta" (Aristóteles, Rhétorique 1451b, 29-33). ${ }^{6}$ Aristóteles escreve exatamente um poeta "fazendo" genomema. O que importa não é que os acontecimentos tenham ocorrido, mas que eles respondam às exigências (inegociáveis) do verossímel e do possível. Alguns comentadores servem-se dessa passagem para sugerir que a poiesis não é completa nem definitivamente interditada para a história. Eu não creio nisso. Aristóteles está preocupado com o poeta e não com o historiador, e aquilo que vale para um não vale, no sentido contrário, 22 para o outro. Por certo, o poeta não está interessado no que aconteceu, mas apenas na medida em que se reconhece nisso uma organização de acordo com o verossímel e o possível, enquanto que o historiador é requisitado, primeiramente, por aquilo que aconteceu (que isso seja da ordem do verossímel ou do possível, ou mesmo necessário, não é, literalmente, seu problema). Para Aristóteles, o historiador não é um "mestre de intrigas" e, no século II de nossa era, Luciano de Samósata o repetirá, a sua maneira: as únicas questões às quais ele deve responder são aquelas da escolha dos genomenas e da maneira de dizê-los.

Evidentemente, outra é a direção de Ricœur. Pois, para validar sua grande hipótese, segundo a qual o tempo pensado somente existe quando narrado, ele deve provar "o caráter, em última análise, narrativo da história", começando por examinar essa história que pretendia, de forma um pouco precipitada, ter renunciado à narrativa. Ele não pode, portanto, partir da separação inicial de Aristóteles que, ao excluir a história da mimesis e da poiesis, resolvia brutalmente a questão. Ele concederá, assim, à história toda a poiesis que for possível, sem, entretanto, comprometer o "primado" de sua intenção referencial. Aqui está todo o desafio do conceito de representância.

\footnotetext{
${ }^{6}$ Diferentemente da citação anterior da Poética de Aristóteles, Hartog não se serve aqui da tradução de $M$. Casevitz, mas da tradução de R. Dupont-Roc e J. Lallot, publicada pela Editora Seuil, em 1980. Para a citação em português de a Poética nos servimos tanto nessa passagem quanto na anterior, bem como da citação de Tucídides, da tradução brasileira da obra de Hartog, A história de Homero a Santo Agostinho, realizada por Jacyntho Lins Brandão, publicada em 2011 pela Editora da UFMG (Nota do revisor).
} 
Partindo do linguistic turn, fomos conduzidos a sugerir um paralelo entre Ricœur e Ginzburg, que nos levou "mais uma vez" a Aristóteles. Talvez esse percurso entre retórica e poética possa ter uma utilidade, ainda que, dos modernos aos antigos e dos antigos aos modernos, ainda faltem algumas etapas?

\section{Referências bibliográficas}

ARISTOTE. Rhétorique. Paris: Gallimard, 1998.

BARTHES, Roland. Le discours de I'histoire:le bruissement de la langue. Essais Critiques IV. Paris: Éd. du Seuil, 1984.

BENVENISTE, Émile. Problèmes de linguistique générale. Paris: Gallimard, 1966. BLANCHOT, Maurice. Après Coup. Paris: Éd. de Minuit, 1983.

BYNUM, Caroline W. Perspectives, Connections, Objects: What's Happening in History Now?, Daedalus, vol. 138, no 1, hiver 2009, p. 71-86.

FRIEDLÄNDER, Saul. Probing the Limits of Representation: Nazism and the "Final Solution". Cambridge (Mass.): Havard University Press, 1992.

GINZBURG, Carlo. Le Sabbat des sorcières. Tradution Monique Aymard. Paris: Gallimard, 1992.

. Rapports de force. Paris: Gallimard, 2003.

. Le fil et les traces: vrai faux fictif. Tradution Martin Rueff. Lagrasse : Verdier, 2010.

HARTOG, François. L'histoire, d'Homère à Augustin. Préfaces des historiens et textes sur l'histoire, réunis et commentés par François Hartog. Tradution par M. Casevitz. Paris: Éd. Le Seuil, 1999.

MOMIGLIANO, Arnaldo. The History Rhetoric and Rhetoric of History: on Hayden White's Tropes. Settimo contributo alla storia degli studi classici e del mondo antico. Rome: Ed. di storia e letteratura, 1984, p. 49-59.

PEETERS, Benoît. Derrida. Paris: Flammarion, 2010.

RICGEUR, Paul. Temps et Récit. Tome I: I'intrigue et le récit historique. Paris: Éd. Seuil, 1983.

Temps et Récit. Tome III: les temps raconté. Paris: Éd. Seuil, 1985. . La mémoire, I'histoire, I’oubli. Paris, Éditions du Seuil, 2000.

SPIEGEL, Gabrielle M. The task of the historian. American Historical Review, vol. 114, no 1, fév. 2009, p. 1-15. 